\title{
Dielectric properties assessment of honey by using non- destructive dielectric spectroscopy
}

\author{
Aslina Abu Bakar ${ }^{1}$, Muhammad Aiman Najmi bin Rodzali ${ }^{2}$, Rosfariza Radzali ${ }^{1}$, \\ Azlina Idris ${ }^{2}$, Ahmad Rashidy Razali ${ }^{1}$ \\ ${ }^{1}$ School of Electrical Engineering, College of Engineering, Universiti Teknologi MARA, Cawangan Pulau Pinang, \\ Kampus Permatang Pauh, Permatang Pauh, Pulau Pinang, Malaysia \\ ${ }^{2}$ School of Electrical Engineering, College of Engineering, Universiti Teknologi MARA, Shah Alam, Malaysia
}

\begin{tabular}{l} 
Article Info \\
\hline Article history: \\
Received Jul 27, 2020 \\
Revised Jul 16, 2021 \\
Accepted 30 Jul, 2021 \\
\hline
\end{tabular}

Keywords:

Dielectric constant

Honey

Open ended coaxial probe

Penetration depth

Water content

\begin{abstract}
In this research the dielectric constant of three types of Malaysian honey has been investigated using a non-destructive measurement technique. The objective of this research is to assess the dielectric constant of the three types of honey in Malaysia using a non-destructive measurement technique known as an open-ended coaxial probe in the frequency range from $100 \mathrm{MHz}$ to $10 \mathrm{GHz}$ frequency. Analysis on the effect water concentration in honey on the dielectric constant and the effect of temperature on dielectric constant of honey has been conducted. The three types of honey that have been chosen to be investigated in this project are stingless bee honey, wild honey and commercial (organic) honey and together their water adulterated samples. For this research, the probe had been set up by setting a range of frequency from $100 \mathrm{MHz}$ to $10 \mathrm{GHz}$ and needs to be calibrated with three calibration methods namely open, short and reference water. From the result it was found that the higher the temperature of the honey and the higher percentage of water content in the honey, the dielectric constant is increased. The dielectric constants of all honeys decreased with increasing frequency in the measured frequency range and increased with increase percentage of water content and temperature.
\end{abstract}

This is an open access article under the $\underline{C C B Y-S A}$ license.

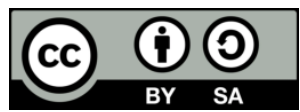

\section{Corresponding Author:}

Aslina Abu Bakar

School of Electrical Engineering, College of Engineering, Universiti Teknologi MARA

Cawangan Pulau Pinang, Permatang Pauh Campus, 13500 Permatang Pauh, Pulau Pinang, Malaysia

Email: aslina060@uitm.edu.my

\section{INTRODUCTION}

Pure honey is very valuable in the market, because of its benefits to health. So, the honey had been used as daily food product for the benefits. Honey consist many vitamin and mineral that good for the human health [1]. One the benefit of honey is it is a good alternative to sugar. Although honey consist sugar, but it is healthier than the sugar. So, it can be replacing sugar as a food sweetener in daily food. Other than that, some research has shown that raw honey can kill unwanted bacteria and fungus. It is reported that it naturally contains hydrogen peroxide, an antiseptic [2].

The honey composition depends on geographical location of where the honey is found [3]. The emergence of synthetic honey and adulterated honey imposes another threat to honey safety and purity due to its relatively high sugar content [4], [5]. One method of adulteration of honey is by the addition of foreign substance directly to honey i.e. by adding water [6]-[8]. Commonly the quality of the honey is measured by sensory and chemical analysis. This type of measurement can be very expensive with a complicated procedure [9]. Therefore, fast, non-destructive, and precise analytical methods are encouraged to complement 
the existing technique [10]. The relative permittivity is a dielectric property that will determines the interaction of food with the electromagnetic field. During the measurement, dielectric probe to measure the dielectric constant has been used at a range of frequencies. Researchers in [11]-[15], has concluded that moisture content being the dominant factor in determining the permittivity of food. Thus, in this paper, water concentration in honey is one of the parameters that has been considered in the analysis. Comparison has been made for all the three types of honey, in terms of temperature variation with frequency and the water concentration of honey across the measured frequencies.

In this paper the non-destructive measurement has been chosen due to its advantage that it does not destroy the material under test, and it is rapid, thus suitable for quality assessment of certain food i.e. honey [10]. This method can provide the dielectric constant value of a material when subjected to an electromagnetic fields [16]-[18]. Besides that, it covers a wide range of frequency and does not require sample preparation. The non-destructive method are increasingly used in the application of agriculture and food processing industries [19]-[21]. With the uses of the open-ended coaxial probe, the honey dielectric constant can be measured and the quality of honey can be assessed using a simple probing technique [12], [16], [17]. The research on the dielectric constant of the honey may be benefit other researcher because of more data on the dielectric constant of honey can be made available and can serve for quality control.

\section{MATERIAL AND METHOD}

\subsection{Types of honey}

For this research, three types of honey has been chosen in the investigation. The three types were stingless bee honey, wild honey and commercial honey as shown in Figure 1. All the honey is used by Malaysian for the daily food consumption, medication or maybe for some specific purposes. All the three honeys are the most popular honey available in the market.

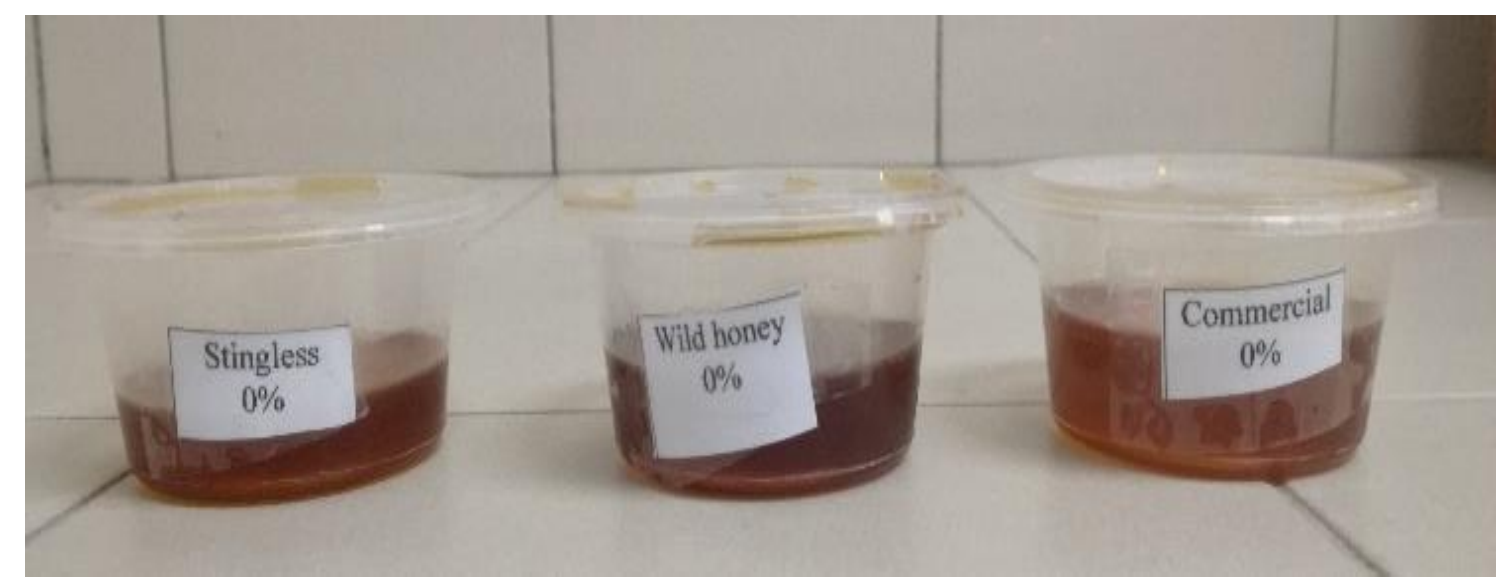

Figure 1. The three-types of honey used in the research: stingless, wild and organic honey

Stingless bee are also popularly known as lebah kelulut in Malaysia with more than 38 stingless bee species [22], [23]. Stingless bee honey is also widely used as medication and it is claimed that it have a high medicinal beneficial than other bee species [6], [24]. Wild bee in the study is name after tualang honey by local people. The honey is produced by the rock bee (apis dorsata), which builds hives on branches of tall Tualang trees located mainly in the north-western region of Peninsular Malaysia. Finally, the commercial honey in this research is a type of honey that has a flower-like aroma. It has a delicate flavor and can be found on acacia mangium trees flowers.

\subsection{Dielectric constant measurement method}

During the measurement, dielectric probe namely keysight 1501A has been used that can measure dielectric constant from the frequency of $10 \mathrm{MHz}$ to $50 \mathrm{GHz}$. Figure 2 shows the coaxial cable probe (N1501A keysight). In this research, a vector network analyzer (E5080B) is connected to high temperature probe with a coaxial cable to measure the dielectric constant of the honey as shown in Figure 3 . The high temperature probe has a frequency range of $100 \mathrm{MHz}$ to $20 \mathrm{GHz}$. The setting had been set from $100 \mathrm{MHz}$ to $10 \mathrm{GHz}$. Before the measurement of the honey is conducted, the probe need to be calibrated. The probe had 
been calibrated using the three standards of calibration, open (air), short circuit and using $25{ }^{\circ} \mathrm{C}$ of deionized water. After the calibration, the deionize water is used as a reference measurement to verify whether the calibration is successful. To do so, the high temperature probe need to be immersed into the deionized water and need to avoid from air bubbles between water and the probe surfaced. Later, the dielectric constant measurement of honey can be resumed.

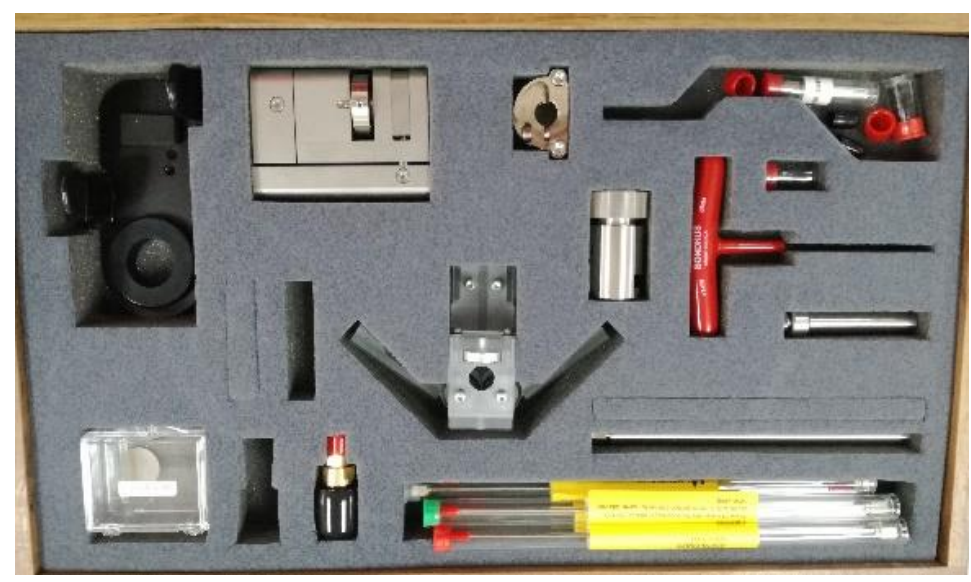

Figure 2. Coaxial cable probe (N1501A keysight)

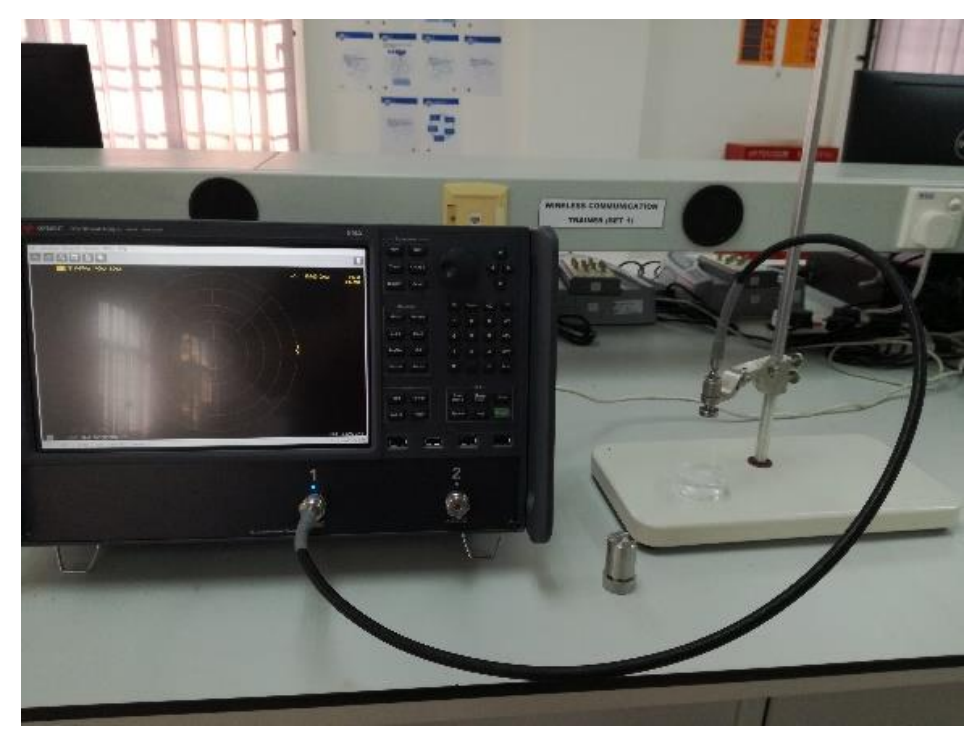

Figure 3. The vector network analyzer connected with the probe for dielectric constant measurement

\subsection{Procedures}

The three types of the honey are poured into $20 \mathrm{ml}$ beaker and labeled. The temperature of the honey is measured by using a digital thermometer and the measurement is conducted at room temperature $\left(25^{\circ} \mathrm{C}\right)$. Then, the honey samples, pure honey and honey with different water content of $10 \%, 20 \%$, and $30 \%$ at room temperature had been prepared for testing. Known amount of deionized water was added to the pure honey, with $10 \%$ water content, of each type to prepare the adulterated honey samples to get a final water contents $(10 \%, 20 \%$, and $30 \%)$ at room temperature.

The calibration consists of measuring three known standards and using the results to characterize the three major sources of measurement error. The default calibration standards are air, a short circuit, and water. After the calibration of the probe, the probe had been adjusted to a suitable height for measurement. Then the probe needs to be completely immersed in the honey sample. In order to get the best result, the air bubble should be eliminated before any measurement to avoid inaccuracy of the results. 
After the dielectric constant at $25^{\circ} \mathrm{C}$ had been measured, the measurement continues with the honey sample been heated to $30{ }^{\circ} \mathrm{C}, 35^{\circ} \mathrm{C}, 40{ }^{\circ} \mathrm{C}, 45^{\circ} \mathrm{C}$, and $50{ }^{\circ} \mathrm{C}$. The honey samples have been heated up by using a laboratory heating plate and need to be stirred until the honey sample totally heated up until to the suitable temperature. After heated up, the sample been measured with the probe until totally immersed and the measurement are measure from $100 \mathrm{MHz}$ to $10 \mathrm{GHz}$. After the measurement, all the dielectric constants had been tabulated and analyzed.

\subsection{Penetration depth}

Penetration depth can be defined as the reducing of electromagnetic power on the surface value [25]. The depth is reducing to $1 / \mathrm{e}$ where $\mathrm{e}=2.7183$ that is about $37 \%$ of its value. The penetration depth can be calculated as in (1):

$$
d_{p}=\frac{c}{2 \pi f \sqrt{2 \varepsilon^{\prime}\left(1+\left(\frac{\varepsilon^{\prime}}{\varepsilon^{\prime \prime}}\right)^{2}-1\right)}}
$$

where:

$c=$ speed of light $(3 \times 108 \mathrm{~m} / \mathrm{s})$

$f=$ frequency in $\mathrm{Hz}$

$\varepsilon^{\prime}=$ dielectric constant

$\varepsilon^{\prime \prime}=$ dielectric loss factor

After all the dielectric constants had be measured. The values are fed into the penetration depth equation as stated in (1). The values of frequency, the value of $\varepsilon^{\prime}$ and $\varepsilon^{\prime \prime}$ had been identified and simulated in MATLAB software to monitor the penetration depth across the frequency with variation of water concentration. The results are discussed in detail in the next section.

\section{RESULTS AND DISCUSSION}

\subsection{Dielectric constant of pure honey}

In this research three types of honey that is stingless bee honey, wild honey and commercial honey had been measure the dielectric constant. The honey been measured at frequency from $100 \mathrm{MHz}$ to $10 \mathrm{GHz}$ at room temperature. The measurement was set from $100 \mathrm{Mhz}$ because the interaction of microwaves with biological material at frequencies above $100 \mathrm{MHz}$ depends more or less exclusively on aqueous and ionic content and thus it could give a better accurate result. This is because at lower frequency, the result on the graph will be rippled and the result will be in error. The result of the dielectric constant can be observed in Figure 4.

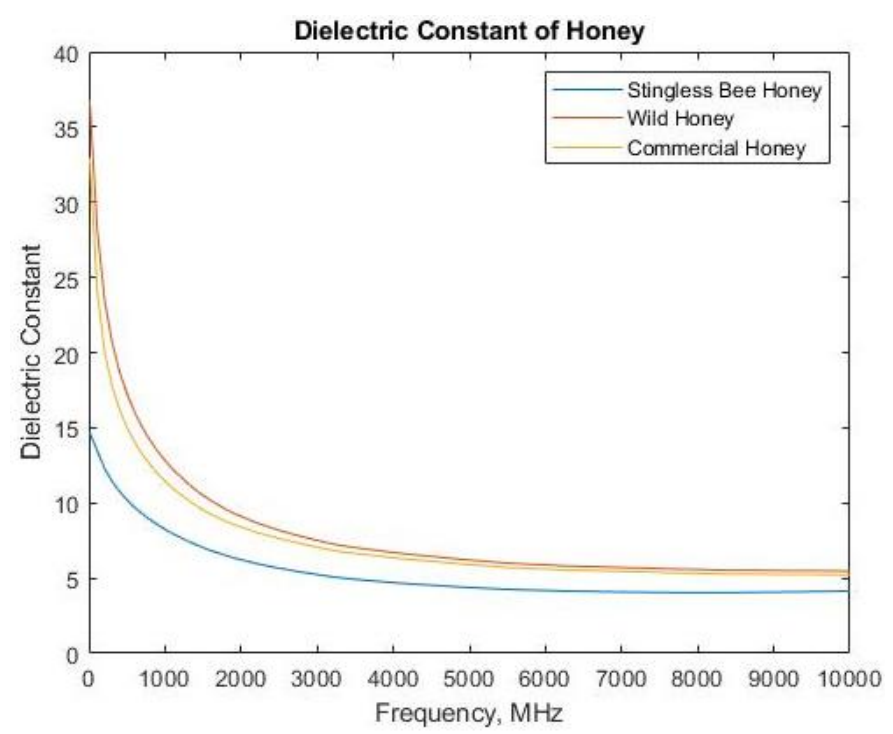

Figure 4. The dielectric constant of the honey 
Figure 4 shows the dielectric constant of the three types of honey with the dielectric constant. The figure shows that the graph of the dielectric constant of the honey decreasing with increasing frequency. It is clearly can be observed that the three types of honey had a decreasing value of dielectric constant with increasing frequency. At some level, it seems the dielectric constant been constant at frequency $5000 \mathrm{MHz}$ and higher.

Based on the Table 1, the stingless bee honey has the lowest dielectric constant at 13.46 when frequency is $100 \mathrm{MHz}$ at $25^{\circ} \mathrm{C}$ and decreasing to $8.21,4.37$, and 4.14 at frequency of $1 \mathrm{GHz}, 5 \mathrm{GHz}$, and $10 \mathrm{GHz}$ respectively. The highest dielectric constant from the three types is from wild honey which was 28.11 at $100 \mathrm{MHz}$ at $25{ }^{\circ} \mathrm{C}$ decreasing to $12.76,6.20$, and 5.47 at frequency $1 \mathrm{GHz}, 5 \mathrm{GHz}$, and $10 \mathrm{GHz}$ respectively. For the commercial honey, although the dielectric constant had a slightly lower than the wild honey, that 24.00 dielectric constant at frequency $100 \mathrm{MHz}$, but it still higher when compared to the stingless honey at $25{ }^{\circ} \mathrm{C}$. Furthermore, the dielectric constant of the commercial honey had decreased with the increasing of the frequency. The dielectric constant of the wild honey is decreased from 24.00 at frequency $100 \mathrm{MHz}$ to $11.40,5.89$, and 5.22 at frequency $1000 \mathrm{MHz}, 5000 \mathrm{MHz}$, and $10000 \mathrm{MHz}$ respectively. Although all the pure honey might contain water, but the water is in a bound form. The dielectric relaxation is likely resulted from bound water according to the frequency where critical frequency appeared in honey. Although honeys have similar content of total soluble solids, other compositions can also have a major impact on their dielectric properties.

Table 1. The dielectric constant of honey at room temperature $\left(25^{\circ} \mathrm{C}\right)$

\begin{tabular}{cccccc}
\hline \multirow{2}{*}{ Honey } & \multirow{2}{*}{ Permittivity } & \multicolumn{4}{c}{ Frequency (MHz) } \\
& & 100 & 1000 & 5000 & 10000 \\
\hline Stingless Bee Honey & $\varepsilon^{\prime}$ & 13.46735 & 8.21695 & 4.377429 & 4.146544 \\
Wild Honey & $\varepsilon^{\prime}$ & 28.11291 & 12.7654 & 6.201249 & 5.471811 \\
Commercial Honey & $\varepsilon^{\prime}$ & 24.00476 & 11.40298 & 5.899014 & 5.220061 \\
\hline
\end{tabular}

Based on the figure, it is found that stingless bee honey has the lowest dielectric constant throughout the measured frequencies. This low dielectric constant of the stingless bee honey may because the stingless bee honey may have lower water content than wild honey and the commercial honey. With low water content in the honey, the dielectric constant value may be low. This is because the content of water can affect the dielectric constant value. The other honey which is wild honey and commercial honey may have a higher bound form of water content than the stingless bee honey.

\subsection{The influence of water content to dielectric constant}

The increasing of water content can influence the value of the dielectric constant. The higher the percentage of the water content that is mixed to the honey, the higher the dielectric constant. Regardless of how much water content was added in stingless bee honey, wild honey and commercial honey, the dielectric constant decreased with increasing frequencies. This result is justified with the result found by Puranik et al. [12]. It was found that the decrease in the relaxation time is caused by the addition of water and thus the dielectric constant is decreased [11]. For this research the water content had been added to $20 \mathrm{ml}$ of honey. The water content will be added as $10 \%, 20 \%$, and $30 \%$ from the honey volume respectively to mimic adulterated honey. For the pure honey, it has the lowest dielectric constant and it increase slowly water content is added.

The Figure 5, Figure 6, and Figure 7 shows the dielectric constant of the three honeys with different water content concentration from $10 \%, 20 \%$, and $30 \%$ at $25{ }^{\circ} \mathrm{C}$ respectively. All the three types of honey have an increased in dielectric constant when water concentration is increased. The dielectric constant of the honey increases slowly with the increasing of water content. For the pure stingless bee honey ( no water is added) ,as shown in Figure 5, the dielectric constant is low at 18.88 at frequency $100 \mathrm{MHz}$ and the dielectric constant is decreased to $10.64,6.39$, and 5.11 at $1000 \mathrm{MHz}, 5000 \mathrm{MHz}$, and $10000 \mathrm{MHz}$ respectively. But the dielectric constant increases with the increasing of water content across the frequency. At 10\%, 20\%, and $30 \%$ of water content, the dielectric constant of the stingless bee honey is at 50.12, 55.77, and 57.35 respectively. For the pure wild honey as shown in Figure 6, the dielectric constant is 29.86, 13.84, 7.60, and 5.40 with frequency $100 \mathrm{MHz}, 1000 \mathrm{MHz}, 5000 \mathrm{MHz}$, and $10000 \mathrm{MHz}$ respectively. The increasing of water content made the dielectric constant of wild honey increase to $44.18,54.26$, and 57.70 at $10 \%, 20 \%$, and $30 \%$ of water content respectively at $100 \mathrm{MHz}$ frequency.

The result is similar for pure commercial honey whereby the dielectric constant increase with increasing water content across the frequency. It can be seen form Figure 7, the dielectric constant also increasing with increasing water content. The dielectric constant of organic honey at water content 
concentration of $0 \%, 10 \%, 20 \%$ and $30 \%$ is $26.09,41.59,55.44$, and 59.20 respectively at frequency of $100 \mathrm{MHz}$. By using this result, the purity of honey can be observed and identified with the volume of water content. The lowest dielectric constant shows that the honey is pure honey, while the higher dielectric constant is because higher content of water presence in the adulterated honey. With this, the purity of honey can be compared using the measured result as a database.

All the changes in the dielectric constant is caused by the ionic behavior. Adding water in honey reduces its viscosity and binding forces to ionic movement, so the ionic conduction plays a growing role in the loss process as the water content increases slowly. It has been identified and shown that ionic conduction is the dominant mechanism of loss in honey [25].

Table 2 shows the table of dielectric constant for different water concentration at four frequencies when measured at $25^{\circ} \mathrm{C}$. The table shows a consistent pattern of the dielectric constant of the three types of honey across the measured frequency, the dielectric constant of all three types of honey decreased with the increase in the frequency. It also can be summarized that the dielectric constant of all types of honey increase with increasing water content across the frequency.

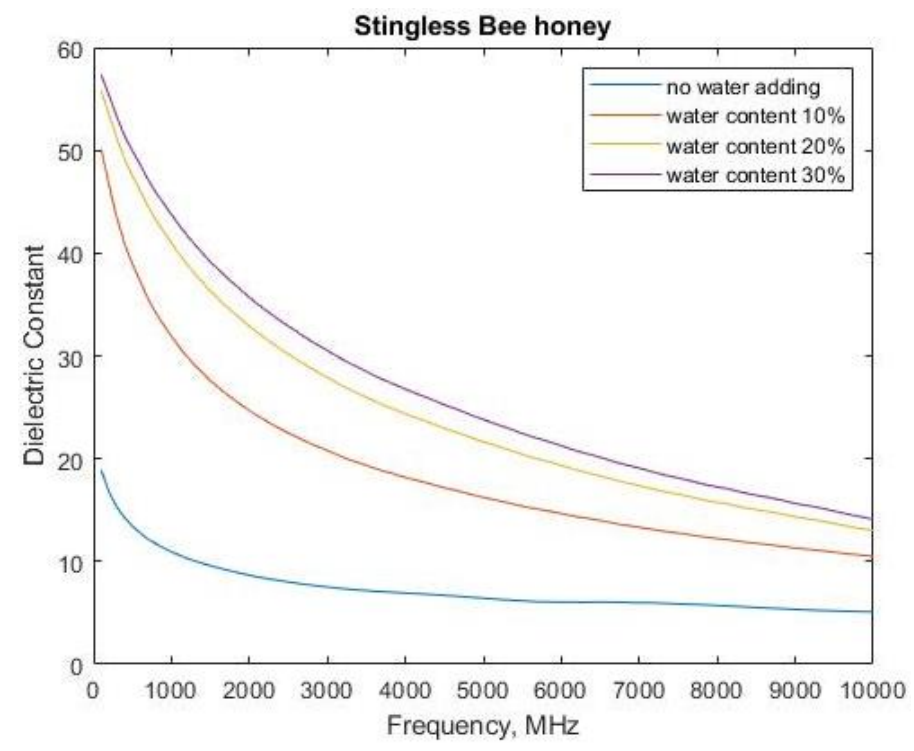

Figure 5. Stingless honey vs the water content

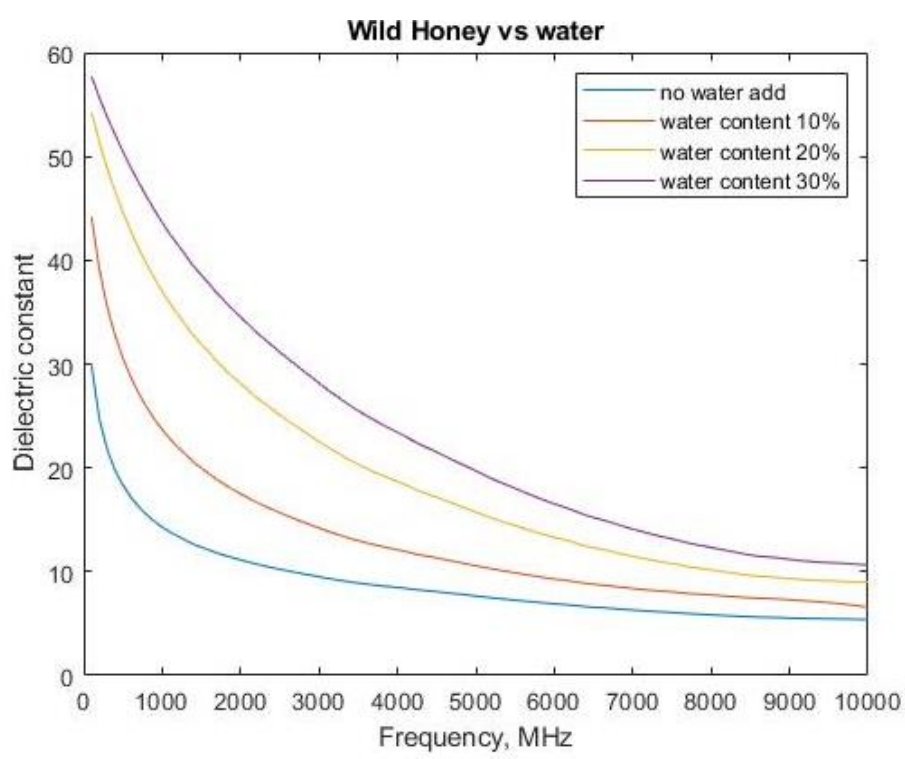

Figure 6. Wild honey vs the water content 


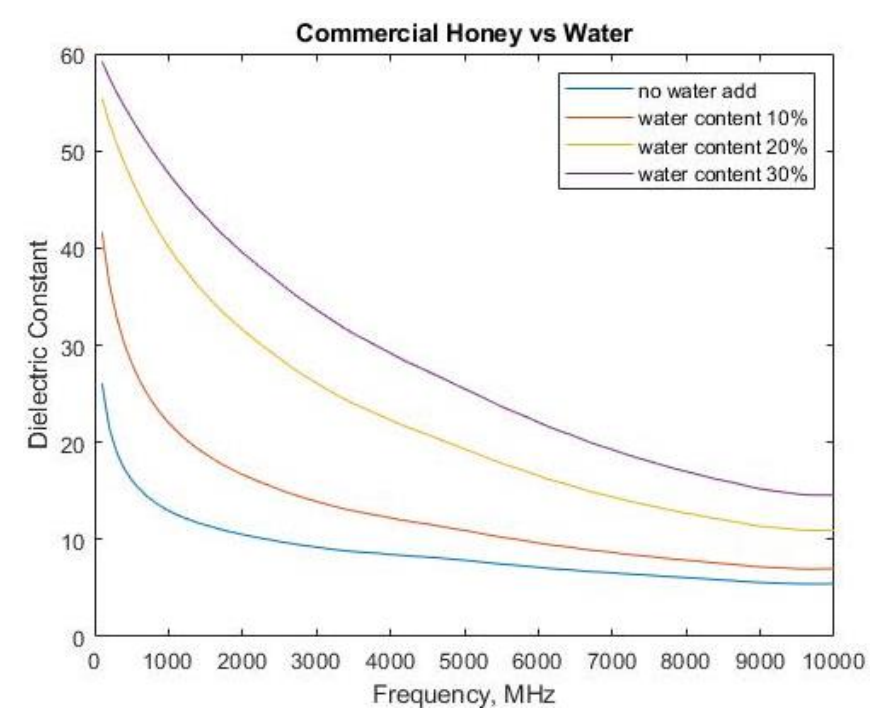

Figure 7. Commercial honey vs the water content

Table 2. The dielectric constant of the honey with difference water content at four frequencies (room temperature $25^{\circ} \mathrm{C}$ )

\begin{tabular}{|c|c|c|c|c|c|c|}
\hline \multirow{2}{*}{ Honey } & \multirow{2}{*}{ Water Content (\%) } & \multirow{2}{*}{ Permittivity } & \multicolumn{4}{|c|}{ Frequency $(\mathrm{MHz})$} \\
\hline & & & 100 & 1000 & 5000 & 10000 \\
\hline \multirow{8}{*}{ Stingless Bee } & \multirow{2}{*}{0} & $\varepsilon^{\prime}$ & 1888249 & 10.64884 & 6393059 & 5.113504 \\
\hline & & $\varepsilon^{\prime \prime}$ & 4398542 & 5.024878 & 3.553934 & 3.120000 \\
\hline & \multirow{2}{*}{10} & $\varepsilon^{\prime}$ & 50.12850 & 30.96371 & 16.15575 & 10.49813 \\
\hline & & $\varepsilon^{\prime \prime}$ & 9.540305 & 14.50191 & 11.86250 & 8.704843 \\
\hline & \multirow{2}{*}{20} & $\varepsilon^{\prime}$ & 55.71556 & 40.00974 & 21.52726 & 12.97834 \\
\hline & & $\varepsilon^{\prime \prime}$ & 9.549713 & 15.70854 & 15.86650 & 12.29473 \\
\hline & \multirow{2}{*}{30} & $\varepsilon^{\prime}$ & 57.35174 & 4280638 & 23.67162 & 14.10279 \\
\hline & & $\varepsilon^{\prime \prime}$ & 9.903941 & 15.64894 & 17.12910 & 13.61364 \\
\hline \multirow{8}{*}{ Wild Honey } & \multirow[b]{2}{*}{0} & $\varepsilon^{\prime}$ & 29.86604 & 13.84707 & 7.604478 & 5.408130 \\
\hline & & $\varepsilon^{\prime \prime}$ & 10.37976 & 7.815738 & 5.014079 & 2.699919 \\
\hline & \multirow{2}{*}{10} & $\varepsilon^{\prime}$ & 44.18429 & 22.85680 & 10.49061 & 6.593671 \\
\hline & & $\varepsilon^{\prime \prime}$ & 9.499322 & 13.18460 & 9.115590 & 5.845393 \\
\hline & \multirow{2}{*}{20} & $\varepsilon^{\prime}$ & 54.26613 & 35.91661 & 15.58577 & 8.976289 \\
\hline & & $\varepsilon^{\prime \prime}$ & 6.335697 & 16.52867 & 15.22887 & 8.560610 \\
\hline & \multirow{2}{*}{30} & $\varepsilon^{\prime}$ & 57.70876 & 42.59458 & 19.50882 & 10.66041 \\
\hline & & $\varepsilon^{\prime \prime}$ & 5.255380 & 16.65569 & 18.58330 & 10.93768 \\
\hline \multirow{8}{*}{ Commercial } & \multirow[b]{2}{*}{0} & $\varepsilon^{\prime}$ & 26.09218 & 12.6253 & 7.826013 & 5.436938 \\
\hline & & $\varepsilon^{\prime \prime}$ & 9.582274 & 6.31586 & 4.205070 & 2.183057 \\
\hline & \multirow[b]{2}{*}{10} & $\varepsilon^{\prime}$ & 41.59280 & 21.29549 & 10.86041 & 6.968466 \\
\hline & & $\varepsilon^{\prime \prime}$ & 9.825606 & 11.69846 & 8.136194 & 4.479214 \\
\hline & \multirow{2}{*}{20} & $\varepsilon^{\prime}$ & 55.44620 & 39.10415 & 19.17738 & 10.93942 \\
\hline & & $\varepsilon^{\prime \prime}$ & 5.613902 & 15.88364 & 16.18908 & 9.866185 \\
\hline & \multirow{2}{*}{30} & $\varepsilon^{\prime}$ & 59.20388 & 46.79525 & 25.34078 & 14.55121 \\
\hline & & $\varepsilon^{\prime \prime}$ & 4.483451 & 15.09244 & 19.24625 & 12.60106 \\
\hline
\end{tabular}

\subsection{The effect of temperature}

In this research, the effect of temperature variation on the dielectric constant had been observed. All the three types of honey had been heated up using heated plate until it reached the target temperature. The temperature for this research is set from $25{ }^{\circ} \mathrm{C}, 30{ }^{\circ} \mathrm{C}, 35^{\circ} \mathrm{C}, 40{ }^{\circ} \mathrm{C}, 45^{\circ} \mathrm{C}$, and $50{ }^{\circ} \mathrm{C}$. After the honey is heated up and the temperature is stabled, the honey will be probed for the dielectric constant measurement across the frequency. Figure 8, Figure 9, and Figure 10 show the dielectric constant of the stingless bee honey, wild honey and organic honey vs temperature respectively.

Figure 8 shows the dielectric constant of stingless bee honey at various temperature. Although the dielectric constant of the stingless bee honey decreases with the increase in frequency, it seems that the temperature had given an effect. The dielectric constant of the stingless bee honey increases dramatic when had been heated up. When the honey at $25{ }^{\circ} \mathrm{C}$ the dielectric constant is 13.80 at frequency $100 \mathrm{MHz}$ but the dielectric constant is increased to 38.04 when temperature is at $30{ }^{\circ} \mathrm{C}$. The highest dielectric constant at frequency of $100 \mathrm{MHz}$ is at 41.72 when measured at temperature $45^{\circ} \mathrm{C}$. There is rapid increment of the 
dielectric constant at temperature $25{ }^{\circ} \mathrm{C}$ to $30{ }^{\circ} \mathrm{C}$. Perhaps because of the hydrogen bonds between water molecules and saccharide molecules are weakening as temperature rises, and the reorientation motions of water molecules would be easier [9]. With that, the dielectric constant will increase with increasing temperature. During and before the measurement the probe is regularly cleaned and wiped and the present of air gap at the surface of the probe is avoided when measurement is done. Table 3 gives the tabulated data of the stingless bee honey with temperature. The table shows the result of the dielectric constant of stingless bee honey at frequency $100 \mathrm{MHz}, 1000 \mathrm{MHz}, 5000 \mathrm{MHz}$ and $10000 \mathrm{MHz}$ and with temperature at $25^{\circ} \mathrm{C}, 30^{\circ} \mathrm{C}$, $35^{\circ} \mathrm{C}, 40{ }^{\circ} \mathrm{C}, 45^{\circ} \mathrm{C}$, and $50{ }^{\circ} \mathrm{C}$ respectively.

The graph in Figure 9 shows for dielectric constant of wild honey with temperature ranges from $25{ }^{\circ} \mathrm{C}, 30{ }^{\circ} \mathrm{C}, 35^{\circ} \mathrm{C}, 40{ }^{\circ} \mathrm{C}, 45^{\circ} \mathrm{C}$, and $50{ }^{\circ} \mathrm{C}$. For the wild honey, the dielectric constant also increases with increasing temperature. The dielectric constant of the wild honey at frequency $100 \mathrm{MHz}$ increases from 22.26 at temperature $25{ }^{\circ} \mathrm{C}$ to 28.18 at temperature $30{ }^{\circ} \mathrm{C}$ in frequency. The lowest dielectric constant of wild honey at frequency of $100 \mathrm{MHz}$ is 22.26 when the honey is at $25{ }^{\circ} \mathrm{C}$ and the highest dielectric constant is 36.53 when the temperature of honey is increased to $50{ }^{\circ} \mathrm{C}$. It is shown that the dielectric constant is increased with the increasing temperature from $25{ }^{\circ} \mathrm{C}$ to $45{ }^{\circ} \mathrm{C}$ but when the temperature is at $50{ }^{\circ} \mathrm{C}$ the dielectric constant is decrease to a lower value. Table 4 shows the tabulated data of the dielectric constant of wild honey with temperature. The table shows the result of wild honey with frequency at $100 \mathrm{MHz}$, $1000 \mathrm{MHz}, 5000 \mathrm{MHz}$ and $10000 \mathrm{MHz}$ with temperature at $25^{\circ} \mathrm{C}, 30^{\circ} \mathrm{C}, 35^{\circ} \mathrm{C}, 40{ }^{\circ} \mathrm{C}, 45^{\circ} \mathrm{C}$ and $50{ }^{\circ} \mathrm{C}$.

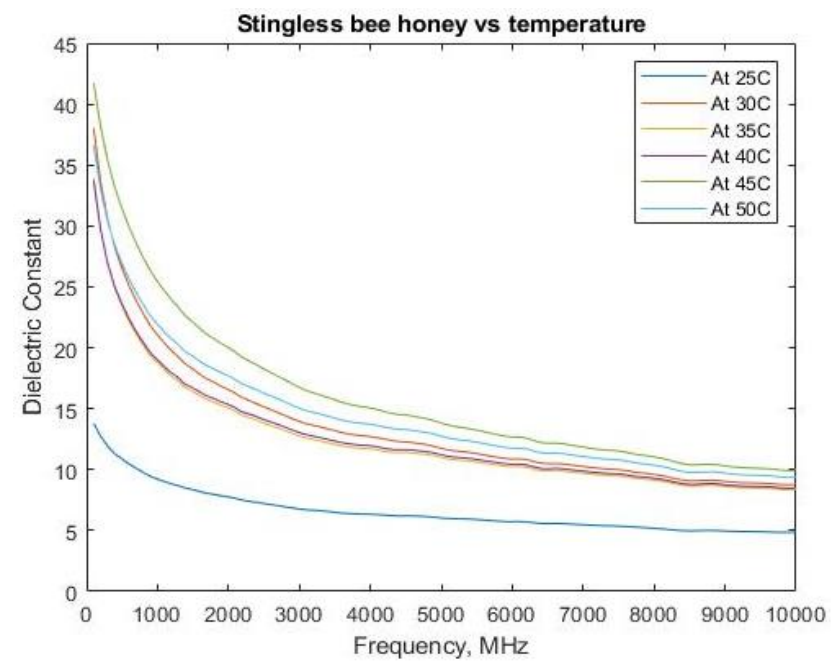

Figure 8. Stingless bee honey vs temperature

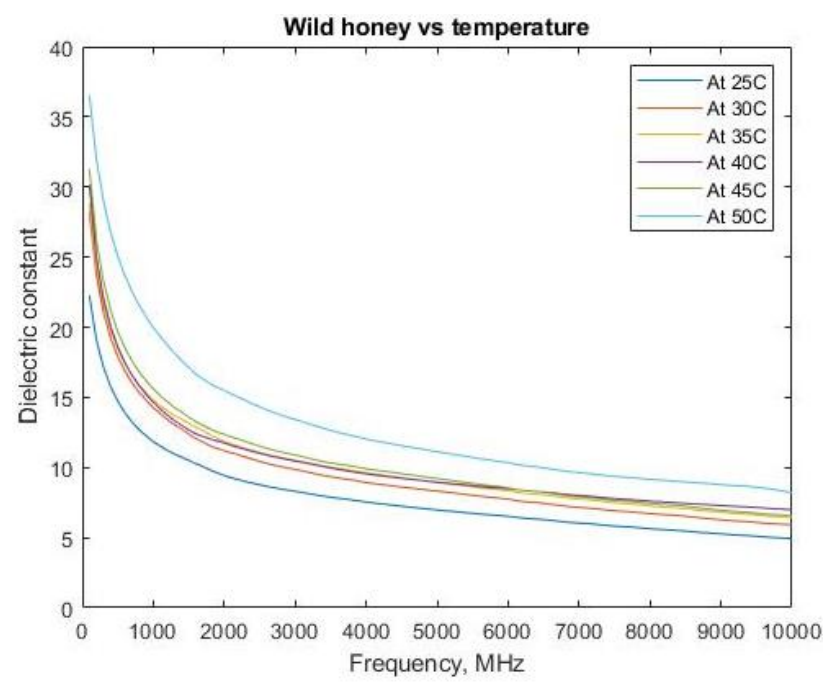

Figure 9. Wild honey vs temperature 
Figure 10 shows the dielectric constant of commercial honey with temperature of $25{ }^{\circ} \mathrm{C}, 30{ }^{\circ} \mathrm{C}$, $35{ }^{\circ} \mathrm{C}, 40{ }^{\circ} \mathrm{C}, 45^{\circ} \mathrm{C}$, and $50{ }^{\circ} \mathrm{C}$. The dielectric constant of commercial honey is decreasing with increasing temperature because of the hydrogen bonds between water molecules and saccharide molecules are weakening as temperature rises, and the reorientation motions of water molecules [25]. The lowest dielectric constant of the commercial honey is 22.94 at temperature $45{ }^{\circ} \mathrm{C}$ and the highest is 28.62 at $50{ }^{\circ} \mathrm{C}$. The decrement can be seen at temperature $25{ }^{\circ} \mathrm{C}, 30{ }^{\circ} \mathrm{C}$, and $35{ }^{\circ} \mathrm{C}$ where the dielectric constant of honey is $26.37,23.67667$, and 24.68 respectively. Irregular pattern is seen when the temperature increases to $45{ }^{\circ} \mathrm{C}$ the dielectric constant is increased but when the temperature increases to $50{ }^{\circ} \mathrm{C}$ the dielectric constant is increase for all the selected frequency.

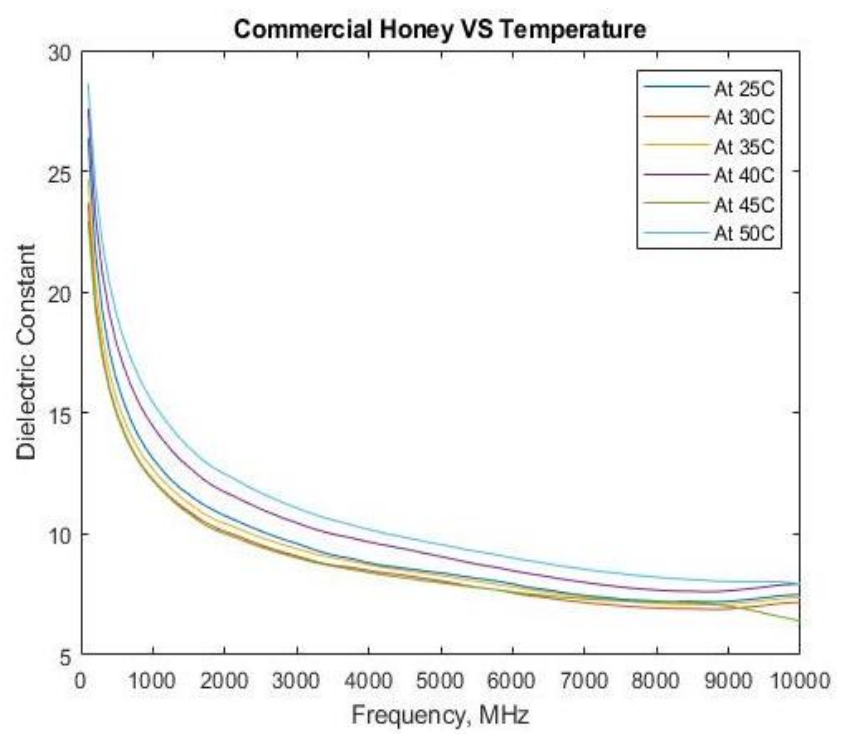

Figure 10. Commercial honey vs temperature

Table 3. The dielectric constant of stingless bee honey with temperature

\begin{tabular}{ccccccc}
\hline \multirow{2}{*}{ Frequency $(\mathrm{MHz})$} & 25 & 30 & 35 & 40 & 45 & 50 \\
\hline 100 & 13.80318 & 38.0404 & 33.97573 & 33.71611 & 41.72636 & 36.61956 \\
1000 & 9.036913 & 20.42367 & 18.20558 & 18.46945 & 24.71557 & 21.3366 \\
5000 & 6.009943 & 11.67778 & 10.9311 & 11.14716 & 13.72811 & 12.65524 \\
10000 & 4.874236 & 8.787185 & 8.384206 & 8.512798 & 9.951243 & 9.39901 \\
\hline
\end{tabular}

Table 4. The dielectric constant of wild honey with temperature

\begin{tabular}{ccccccc}
\hline \multirow{2}{*}{ Frequency $(\mathrm{MHz})$} & 25 & 30 & 35 & 40 & 45 & 50 \\
\hline 100 & 22.26243 & 28.18403 & 28.82208 & 30.14319 & 31.29385 & 36.53337 \\
1000 & 11.5351 & 13.86211 & 14.42909 & 14.19624 & 15.15291 & 19.38178 \\
5000 & 6.946636 & 8.285865 & 8.891872 & 8.891872 & 9.175980 & 11.08344 \\
10000 & 4.925227 & 5.904124 & 6.416336 & 6.98545 & 6.560615 & 8.172779 \\
\hline
\end{tabular}

\subsection{The penetration depth of honey}

The Table 5 shows the tabulated data of penetration depth after all the measured dielectric constant has been obtained. All the measured value will be inserted into penetration depth equation and run using a MATLAB software. This research shows that the higher the frequency, the lower the value of the penetration depth. It is shown that the frequency had been the main factor in getting the value of the penetration depth.

Figure 11 shows the penetration depth of stingless bee honey by using the equation of penetration depth. The data shows that the higher the frequency, the lower the penetration depth. This is because when the frequency increased, the dielectric constant will decrease. It might lead to decreasing of the penetration depth. Furthermore, the water content also effecting the penetration depth. The higher the concentration of water content in honey, the higher the penetration depth with decreasing in frequency. 
Table 5. Penetration depth of stingless honey at $10 \%, 20 \%$, and $30 \%$ at $25{ }^{\circ} \mathrm{C}$ in $\mathrm{m}$

\begin{tabular}{ccccc}
\hline \multirow{2}{*}{ Honey } & \multirow{2}{*}{ Frequency $(\mathrm{MHz})$} & \multicolumn{3}{c}{ Water Content $(\%)$} \\
& 100 & 0.3559 & 0.3748 & 0.3664 \\
Stingless Honey & 1000 & 0.0188 & 0.0916 & 0.0203 \\
& 5000 & 0.0034 & 0.0030 & 0.0029 \\
& 10000 & 0.0019 & 0.0000 & 0.0014 \\
\hline
\end{tabular}

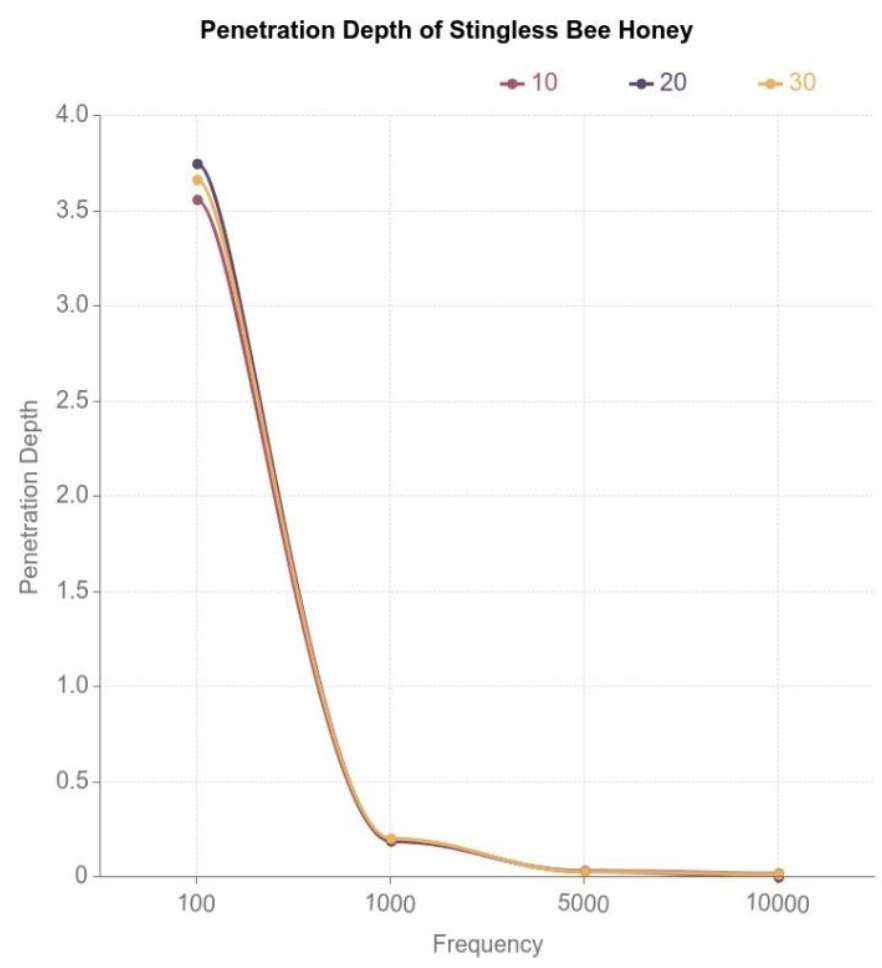

Figure 11. Penetration depth of stingless bee honey at 10\%, 20\%, 30\% of water content

\section{CONCLUSION}

From the measured data, it is found that frequency, concentration of water and temperature has effect on the dielectric constant of honey. The dielectric constants of pure honeys and honey solutions decreased with increasing frequency in the studied frequency range,and increased with water content. Adding water in honey reduces its viscosity and binding forces to ionic movement, so the ionic conduction plays a growing role in the loss process as the water content increases slowly and leads to increase in the dielectric constant. Of all the honey sample, the stingless bee honey had the lowest dielectric constant compared to wild honey and the commercial honey. The result may be because the stingless bee honey had the lowest concentration of water and lead to lower dielectric constant than other type of honey. When the temperature of the honey sample is increasing up to $30{ }^{\circ} \mathrm{C}, 35^{\circ} \mathrm{C}, 40{ }^{\circ} \mathrm{C}, 45^{\circ} \mathrm{C}$, and $50{ }^{\circ} \mathrm{C}$, the dielectric constant of the honey will be increased too. This is because of the hydrogen bonds between water molecules and saccharide molecules are weakening as temperature rises and lead to higher dielectric constant to the honey. The penetration depth of electromagnetic energy in all types of honey decreased with increased frequency. The data been compared with the difference frequency, water content and with a variation of temperature. If an unknown honey is measured or probed and the result was found to be much higher than the measured dielectric constant of pure honey, or lies in between the adulterated range, the purity of honey can be determined. So, the measured data can be helpful in determining the purity of the mentioned types of honey by referring to the measured dielectric constant produced as a reference.

\section{ACKNOWLEDGEMENTS}

The authors gratefully acknowledged Universiti Teknologi Mara, Cawangan Pulau Pinang, Malaysia for the financial support. 


\section{REFERENCES}

[1] I. Flanjak, D. Kenjerić, D. Bubalo, and L. Primorac, "Characterisation of selected croatian honey types based on the combination of antioxidant capacity, quality parameters, and chemometrics," European Food Research and Technology, vol. 242, no. 4, pp. 467-475, 2016, doi: 10.1007/s00217-015-2557-0.

[2] M. D. Mandal and S. Mandal, "Honey: its medicinal property and antibacterial activity," Asian Pacific Journal of Tropical Biomedicine, vol. 1, no. 2, pp. 154-160, 2011, doi: 10.1016/S2221-1691(11)60016-6.

[3] N. I. B. Ismail, "Characterisation of Malaysian honeys and electrochemical detection of gallotannin for pure honey identification," Ph.D. dissertation, Faculty of Biosciences and Medical Engineering, Universiti Teknologi Malaysia, 2017.

[4] K. M. Yusoff, J. Hamid, and M. N. A. Manap, "The presence of synthetic and adulterated honeys in Malaysia," Malaysian Journal of Medical Sciences, vol. 14, no. 1, 2007.

[5] P. N. S. M. Dan, S. Omar, and W. I. W. Ismail, "Physicochemical analysis of several natural malaysian honeys and adulterated honey," in IOP Conference Series: Materials Science and Engineering, vol. 440, no. 1, 2018, Art. no. 012049, doi: 10.1088/1757899X/440/1/012049.

[6] R. Biswa, A. Sarkar, and S. S. Khewa, "Ethnomedicinal uses of honey of stingless bee by Nepali community of Darjeeling foothills of West Bengal, India," Indian Journal of Traditional Knowledge, vol. 16, no. 4, pp. 648-653, 2017.

[7] M. Taleuzzaman, M. J. Alam, C. Kala, and I. Rahat, "Honey of authenticity: an analytical approach," Therapeutic Applications of Honey and its Phytochemicals, pp. 101-120, 2020, doi: 10.1007/978-981-15-6799-5_6.

[8] W. Guo, Y. Liu, X. Zhu, and S. Wang, "Dielectric properties of honey adulterated with sucrose syrup," Journal of Food Engineering, vol. 107, no. 1, pp. 1-7, 2011, doi: 10.1016/j.jfoodeng.2011.06.013.

[9] N. L. Chin and K. Sowndhararajan, "A review on analytical methods for honey classification, identification and authentication," Honey Analysis-New Advances and Challenges, 2020, doi: 10.5772/intechopen.90232.

[10] S. Kono, H. Imamura, and K. Nakagawa, "Non-destructive monitoring of food freezing process by microwave resonance spectroscopy with an open-ended coaxial resonator," Journal of Food Engineering, vol. 292, 2021, Art. no. 110293, doi: 10.1016/j.jfoodeng.2020.110293.

[11] U. Kaatze and V. Uhlendorf, "The dielectric properties of water at microwave frequencies," Zeitschrift für Physikalische Chemie, vol. 126, no. 2, pp. 151-165, 1981, doi: 10.1524/zpch.1981.126.2.151.

[12] S. Puranik, A. Kumbharkhane, and S. Mehrotra, "Dielectric properties of honey-water mixtures between $10 \mathrm{MHz}$ to $10 \mathrm{GHz}$ using time domain technique," Journal of Microwave Power and Electromagnetic Energy, vol. 26, no. 4, pp. 196-201, 1991, doi: $10.1080 / 08327823.1991 .11688157$.

[13] M. Yang, Y. Gao, Y. Liu, X. Fan, K. Zhao, and S. Zhao, "Broadband dielectric properties of honey: effect of water content," Journal of Agricultural Science and Technology, vol. 20, no. 4, pp. 685-693, 2018.

[14] S. Ryynänen, "The electromagnetic properties of food materials: a review of the basic principles," Journal of food engineering, vol. 26, no. 4, pp. 409-429, 1995, doi: 10.1016/0260-8774(94)00063-F.

[15] I. Singh and S. Singh, "Honey moisture reduction and its quality," Journal of food science and technology, vol. 55, no. 10, pp. 3861-3871, 2018, doi: 10.1007/s13197-018-3341-5.

[16] Y. Sato, N. Ogura, Y. Yamaguchi, and Y. Ju, "Development of a sensor for dielectric constant measurements utilizing timedomain measurement with a vector network analyzer," Measurement, vol. 169, pp. 108530, 2021, doi: 10.1016/j.measurement.2020.108530.

[17] K. Pentoś and D. Luczycka, "Dielectric properties of honey: the potential usability for quality assessment," European Food Research and Technology, vol. 244, no. 5, pp. 873-880, 2018, doi: 10.1007/s00217-017-3011-2.

[18] D. Euczycka and K. Pentoś, "The use of dielectric honey features for overheating diagnostics," Acta Alimentaria, vol. 48, no. 1, pp. 28-36, 2019.

[19] Z. Hlaváčová, "Low frequency electric properties utilization in agriculture and food treatment," Research in Agricultural Engineering, vol. 49, no. 4, pp. 125-126, 2003, doi: 10.17221/4963-RAE.

[20] S. O. Nelson, "Dielectric properties of agricultural products-measurements and applications," in IEEE transactions on Electrical Insulation, vol. 26, no. 5, pp. 845-869, 1991, doi: 10.1109/14.99097.

[21] S. O. Nelson, "Dielectric spectroscopy in agriculture," Journal of Non-Crystalline Solids, vol. 351, no. 33, 2005, doi: 10.1016/j.jnoncrysol.2005.04.081.

[22] M. Z. Mustafa, N. S. Yaacob, and S. A. Sulaiman, "Reinventing the honey industry: opportunities of the stingless bee," The Malaysian Journal of Medical Sciences, vol. 25, no. 4, pp. 1, 2018, doi: 10.21315/mjms2018.25.4.1.

[23] B. A. Souza et al., "Composition of stingless bee honey: setting quality standards," Interciencia, vol. 31, no. 12, pp. 867-875, 2006

[24] B. Chuttong, Y. Chanbang, K. Sringarm, and M. Burgett, "Physicochemical profiles of stingless bee (apidae: meliponini) honey from South East Asia (Thailand)," Food Chemistry, vol. 192, pp. 149-155, 2016, doi: 10.1016/j.foodchem.2015.06.089.

[25] W. Guo, X. Zhu, Y. Liu, and H. Zhuang, "Sugar and water contents of honey with dielectric property sensing," Journal of Food Engineering, vol. 97, no. 2, pp. 275-281, 2010, doi: 10.1016/j.jfoodeng.2009.10.024.

\section{BIOGRAPHIES OF AUTHORS}

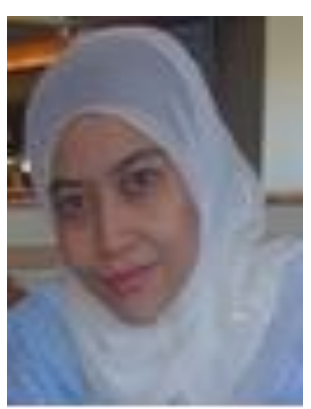

Aslina Abu Bakar (iD) SC S P obtained her Ph.D. in Electrical Engineering from University of Queensland. Her research interest includes microwave imaging, wearable antenna and UWB microwave imaging applications. She can be contacted at email: aslina060@uitm.edu.my. 


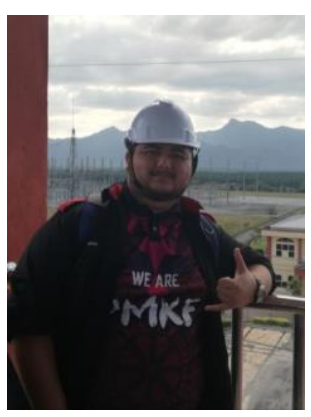

Muhammad Aiman Najmi bin Rodzali (D) $8 \mathrm{SC}$ P received the B. Eng. (Hons) degree in Electrical and Electronic Engineering from the Universiti Teknologi MARA (UiTM) Malaysia. He can be contacted at email: $2016589391 @$ isiswa.uitm.edu.my.

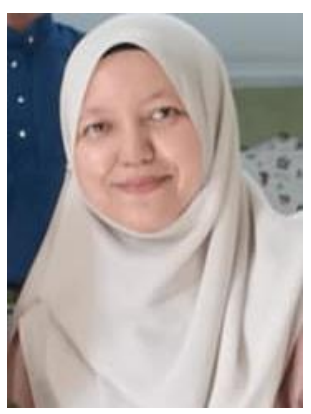

Rosfariza Radzali (D) BI SC P obtained her Ph.D. from Universiti Sains Malaysia. Her research interests are semiconductor devices, nanostructure fabrication (III-nitrides \& silicon) and gas sensor device. She can be contacted at email: rosfariza074@uitm.edu.my.

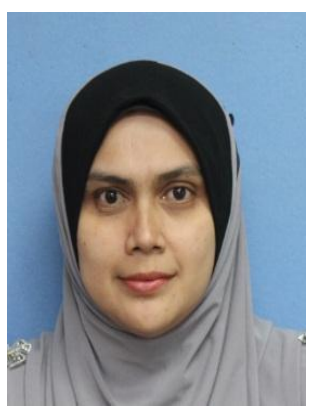

Azlina Idris (D) 8d SC P currently working at UiTM Shah Alam, Malaysia. Her research interest is in the area of wireless communication and MIMO. She can be contacted at email: azlina831@uitm.edu.my.

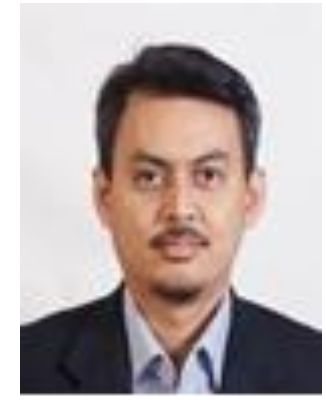

Ahmad Rashidy Razali (iD 8 SC P holds a Ph.D. degree in Electrical Engineering from University of Queensland, Australia. His research interests are in the area of antenna and microwave. He can be contacted at email: ahmadrashidy@gmail.com. 